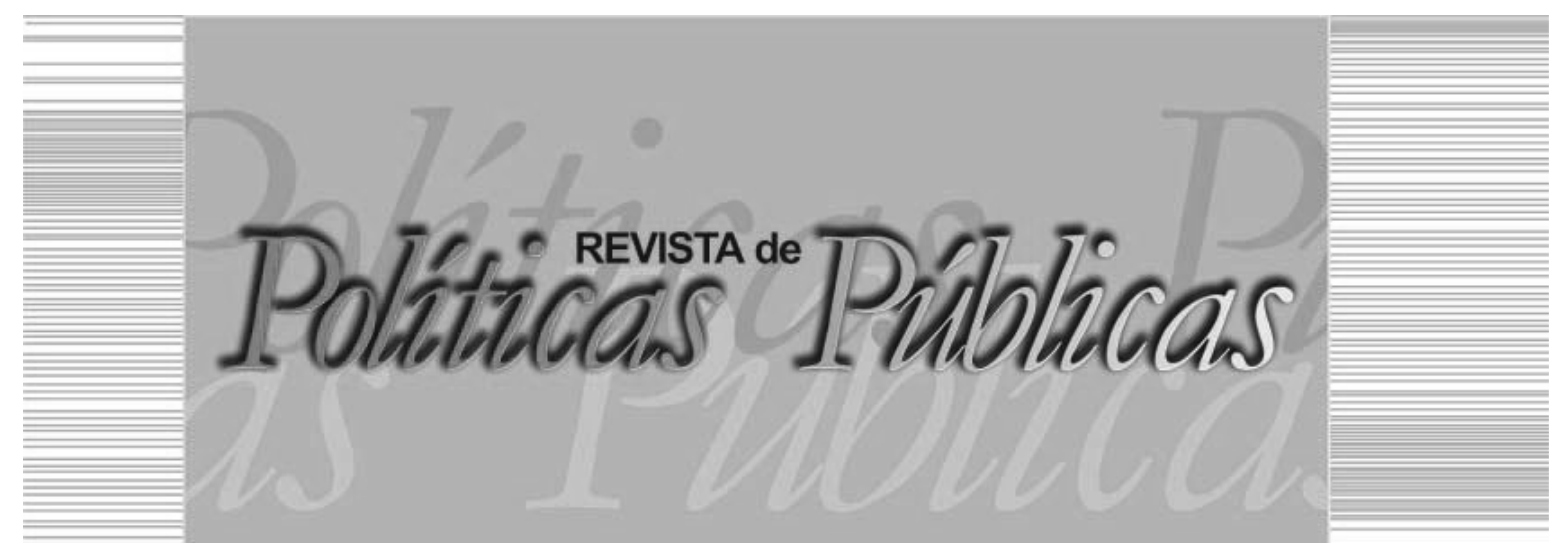

\title{
O VALE CULTURA NA VISÃO DE GESTORES DE EMPRESAS DE UM MUNICÍPIO DO SUL DO BRASIL
}

\author{
Ana Clara Ferreira Marques ${ }^{l}$ \\ Maria Glória Dittrich ${ }^{2}$
}

Micheline Ramos de Oliveira ${ }^{3}$

Flávio Ramos ${ }^{4}$

\section{Resumo}

A Lei Federal no 12.761/2012 instituiu o Programa de Cultura do Trabalhador para garantir a implementação de direitos culturais aos trabalhadores e incentivar a cadeia produtiva da cultura. Este artigo é resultante de uma pesquisa com objetivo de perceber como se dá o processo de implantação deste programa, em Itajaí - SC. A pesquisa foi do tipo exploratória, qualiquantitativa, sob a abordagem da hermenêutica fenomenológica. O público alvo foi composto por

1 Relações Públicas, Mestre em Gestão de Políticas Públicas pela Universidade do Vale do Itajaí(UNIVALI)/SC, vinculada a Sociedade Educacional do Vale do Itajaí Mirim, Faculdade do Vale do Itajaí Mirim (FAVIM) Grupo Uniasselvi - Unidade Brusque, Professora do Curso de Publicidade e Propaganda da Uniasselvi/Assevim. E-mail: anaclarafmarques@ gmail.com / Endereço: Grupo Uniasselvi: Espaço Schlöesser/Havan - Av. Getúlio Vargas, 35 A - Centro 1, Brusque - SC. CEP: 88351-350

2 Filósofa, Doutora em Teologia pela Escola Superior de Teologia, Professora Pesquisadora do Programa de Mestrado Profissional em Gestão de Políticas Públicas (PMGPP) da UNIVALI. E-mail: gloria.dittrich@univali.br / Endereco: Universidade do Vale do Itajaí - UNIVALI: Programa de Mestrado em Gestão de Políticas Públicas Rua Uruguai, 458 - Setor D 1 - Sala 401, Itajaí - SC. CEP 88.302-901

3 Graduação, Doutora em Antropologia social pelo Programa Pós-Graduação em Antropologia Social (PPGAS) da Universidade Federal de Santa Catarina (UFSC), Professora titular do PMGPP/UNIVALI. E-mail: micheantr@hotmail.com

4 Graduaçao, Doutor em Sociologia Política pela UFSC, Professor titular do PMGPP/ UNIVALI. E-mail: flauni@univali.br 
empresas itajaienses optantes do lucro real. A coleta de dados realizou-se por pesquisa bibliográfica e documental e por entrevistas estruturadas individuais, com três gestores e três trabalhadores por empresa. $\mathrm{O}$ resultado mostrou que os gestores não percebem viabilidade econômica nesta política, nem benefício aos trabalhadores devido à diminuta rede credenciada local de recebedoras do Vale Cultura.

Palavras-chave: Vale cultura, isenção fiscal, comunicação, qualidade de vida.

\title{
THE CULTURE'S VOUCHER FROM THE VIEW OF BUSINESS MANAGEMENT IN A SOUTH OF BRAZIL CITY
}

\begin{abstract}
Federal Law No. 12.761 / 2012 established the Worker's Culture Program to ensure the implementation of cultural rights for workers and to encourage the production chain of culture. This article is the result of a research aiming to understand how the implementation process of this program occurs in Itajaí - SC. The research was exploratory, qualitative and quantitative, under the approach of phenomenological hermeneutics. The target public was composed of companies from the city of Itajaí, that opted for tax category 'real profits'. Data collection was done by bibliographic and documentary research and by individual structured interviews, with three managers and three employees per company. The result showed that the managers do not perceive economic viability in this policy, neither benefit to the workers due to the small local accredited network of Vale Cultura recipients.

Key words: Culture Valley, fiscal exemption, communication, quality of life.
\end{abstract}

\section{INTRODUÇÃO}

O Vale Cultura, como é conhecido o Programa de Cultura do Trabalhador, foi estabelecido pela meta 26 do Plano Nacional de Cultura (PNC) do Brasil e visa incentivar a cadeia produtiva da cultura e ao mesmo tempo garantir o exercício dos direitos culturais dos trabalhadores. (BRASIL, 2013a, p. 79). Suas metas são alcançar a distribuição de 12 milhões de cartões Vale Cultura aos trabalhadores, com renda entre 1 e 5 salários mínimos, e desta forma, injetar no mercado cultural cerca de 7,2 bilhões de reais ao ano, até 2020. (BRASIL, 2012b). Instituído pela Lei Federal $n^{\circ} 12.761$, de 27 de dezembro de 2012, o programa está em implementação em todos os estados brasileiros.

O IBGE estima que a população itajaiense em 2015, ano da pesquisa, era de 205.271 pessoas. A economia do município é foca- 


\section{O VALE CULTURA NA VISÃO DE GESTORES DE EMPRESAS DE UM MUNICÍPIO DO SUL DO BRASIL}

da na atividade portuária e desta derivam o comércio exterior, atividades de logística, construção naval, pesca e comércio local. Os dados mais recentes sobre o PIB municipal são de 2012, totalizando R \$ 19,75 bilhões neste ano. O censo de 2010 indica que o Índice de Desenvolvimento Humano Municipal (IDHM) era de 0,795, o $13^{\circ}$ maior entre os 295 municípios de Santa Catarina. Em relação à renda, $87,8 \%$ da população economicamente ativa recebiam até 5 salários mínimos, em 2010. (INSTITUTO BRASILEIRO DE GEOGRAFIA E ESTATÍSTICA, 2010). Essa faixa salarial configura o público alvo do Programa de Cultura do Trabalhador. Portanto, em princípio, a maioria da população trabalhadora de Itajaí tem potencial para receber o cartão Vale Cultura, caso se adeque às demais normativas do programa.

Diante disso, o objetivo deste artigo é apresentar os resultados da pesquisa sobre o Processo de Implementação do Programa de Cultura do Trabalhador (Vale Cultura), no Município de Itajaí, com dois focos principais, a saber: 1) Identificar o nível de implantação e a abrangência da rede credenciada de empresas recebedoras do cartão Vale Cultura em Itajaí; 2) Compreender a percepção dos gestores de empresas itajaienses sobre o processo de implantação do Programa de Cultura do Trabalhador, no município. $\mathrm{O}$ artigo apresenta primeiro o contexto de elaboração do Plano Nacional de Cultura. Em seguida, apresenta-se a metodologia utilizada, o delineamento geral do Programa de Cultura do Trabalhador e os resultados, apontando a visão de gestores empresariais sobre o Vale Cultura em Itajaí. Finaliza-se com as considerações finais.

2 PROGRAMA DE CULTURA DO TRABALHADOR: Uma perspectiva do contexto de elaboração

O Plano Nacional de Cultura, suas metas, programas e as políticas culturais que dele se capilarizaram estão todos embasados no mesmo conceito de cultura atualmente adotado pelo Ministério da Cultura. "Essa concepção compreende uma perspectiva ampliada da cultura, que articula três dimensões: a simbólica, a cidadã e a econômica." (BRASIL, 2013a, p. 15).

Pela perspectiva de sua execução, política cultural é definida por Coelho (1997, p. 292) como: "[...] programa de intervenções realizadas pelo Estado, com o objetivo de satisfazer as necessidades culturais da população e promover o desenvolvimento de suas re- 
presentações simbólicas". Rubim (2007) enfatiza a importância da participação social na elaboração e monitoramento das políticas públicas. Nesse sentido, o cidadão não é apenas um beneficiário, mas agente de transformação da sociedade.

Assim, o Plano Nacional de Cultura foi elaborado em um extenso processo de participação social. Entre 2003 e 2010 ocorreram diversos momentos de pactuação, como: seminários para discussão e diagnóstico da cultura nacional, a instalação de câmaras setoriais por segmento artístico, a $1^{\mathrm{a}}$ e $2^{\mathrm{a}}$ Conferências Nacionais de Cultura, a criação do Conselho Nacional de Políticas Culturais e a aprovação da Emenda Constitucional (EC) $n^{\circ} 48$, de 10 de agosto de 2005, que acrescentou o parágrafo $3^{\circ}$ no artigo $215^{\circ}$, criando o Plano Nacional de Cultura (PNC). (BRASIL, 2012a, p. 57 e 87). Este foi detalhado e instituído pela Lei $\mathrm{n}^{\circ} 12.343$, de 2 de dezembro de 2010. (BRASIL, 2010). A partir desse momento o Ministério da Cultura (MinC) passou a elaborar as metas para alcançar os objetivos nele determinados. O Programa de Cultura do Trabalhador é a meta $\mathrm{n}^{\circ} 26$. (BRASIL, 2013a).

\subsection{Metodologia}

A pesquisa foi exploratória, qualiquantitativa. A compreensão sobre os dados se deu a partir da hermenêutica fenomenológica, apoiada pelo referencial teórico e percepções sobre os dados levantados na pesquisa bibliográfica e documental, bem como, pelos dados obtidos nas entrevistas realizadas junto às empresas, durante a realização dos objetivos. Segundo Dittrich (2008, p. 63), hermenêutica é "[...] uma maneira de entender e expressar a percepção sobre os dados da investigação teórico-prática, de forma qualitativa. A hermenêutica nasce da busca de respostas do pesquisador para seus questionamentos".

A fenomenologia é o estudo das essências, é uma filosofia que compreende o homem e o mundo a partir da sua factibilidade. Trata-se de descrever e não explicar, nem de analisar (MERLEAU-PONTY, 1999). Nesse sentido, a compreensão dos dados da pesquisa se desenvolveu da seguinte forma: Indutivamente foi feita a descrição dos dados coletados na realidade pesquisada junto às empresas itajaienses e na pesquisa documental.O desenvolvimento da compreensão dos dados se deu por meio da percepção dos pesquisadores sobre os registros de significações dos participantes, quando foram 


\section{O VALE CULTURA NA VISÃO DE GESTORES DE EMPRESAS DE UM MUNICÍPIO DO SUL DO BRASIL}

cruzados os dados obtidos com as referências teóricas utilizadas, chegando-se, assim, às considerações finais.

Dentro da fenomenologia, o olhar perceptivo dos pesquisadores, naturalmente, é perpassado pela dinâmica criativa de processos da percepção, que se estruturam entre a sensibilidade intuitiva, intencional e racional, na qual a objetividade e a subjetividade são relacionais às referências qualitativas e quantitativas, que se implicam na complexidade do fenômeno pesquisado - o Programa de Cultura do Trabalhador (Vale Cultura) e a sua implantação no município de Itajaí.

O público alvo foi composto por oito empresas com sede em Itajaí, que representam diferentes áreas de produção no município e atuam no regime tributário de lucro real ${ }^{1}$. Em cada empresa foram entrevistados três gestores: um Diretor/Presidente, um responsável pelo setor Contábil/Financeiro e um responsável pelo setor de RH/ Gestão de pessoas.

A identificação das empresas participantes se fez por meio de consulta direta à Secretaria Municipal da Fazenda, bem como a empresas de contabilidade do município, aos sites da Receita Federal e Ministério da Cultura. Como instrumentos de coleta de dados, utilizaram-se questionários elaborados para cada categoria de gestão, com perguntas diretivas e não diretivas, qualitativas e quantitativas. A forma de aplicação do questionário foi através de entrevista individual. As perguntas visavam identificar a percepção dos mesmos sobre o delineamento dessa política, suas vantagens e desvantagens para as empresas e seus funcionários, bem como fatores relevantes para sua implementação, e a percepção de viabilidade ou não da adesão das empresas ao Programa de Cultura do Trabalhador.

\subsection{Aspectos documentais legais do delineamento do Programa de Cultura do Trabalhador}

O Programa de Cultura do Trabalhador está embasado em conceitos e princípios legais, que versam sobre os direitos culturais e definem o papel do Estado como responsável pela universalização do acesso à cultura no país, previsto na legislação: no art. $215^{\circ}$ da Constituição Federal (CF) de 1988; nos três primeiros artigos da Lei $\mathrm{n}^{0} 12.343$, de 2 de dezembro de $2010^{2}$ que institui o Plano Nacional de Cultura e aponta seus princípios, objetivos e as competências do Estado em sua execução (BRASIL, 2010); na Lei Federal n ${ }^{\circ}$ 
Ana Clara Ferreira Marques | Maria Glória Dittrich

Micheline Ramos de Oliveira | Flávio Ramos

12.761/2012 e também no site do MinC/Vale Cultura, o qual indica que "[...] o Vale Cultura é a primeira política de acesso à cultura disponibilizada pelo governo federal”. (BRASIL, 2015a).

O detalhamento do Programa de Cultura do Trabalhador é feito por meio da Lei Federal $n^{\circ} 12.761 / 2012$, regulamentada pelo Decreto Presidencial $\mathrm{n}^{\circ} 8.084$, de 26 de agosto de 2013. As normas e procedimentos para gestão do Vale Cultura estão definidos nas Instruções Normativas (IN) n ${ }^{0} 2$ e n ${ }^{0} 3$ de 2013. Os objetivos do programa são: “[...] possibilitar o acesso e a fruição dos produtos e serviços culturais; estimular a visitação a estabelecimentos culturais e artísticos; e incentivar o acesso a eventos e espetáculos culturais e artísticos." (BRASIL, 2012b).

O Vale Cultura é confeccionado e comercializado por empresas operadoras e disponibilizado aos trabalhadores pelas empresas beneficiárias para ser utilizado nas empresas recebedoras. Essas empresas devem se cadastrar junto ao Ministério da Cultura para receber certificado de habilitação à participação no programa. As empresas operadoras cadastram as recebedoras. Trata-se de um cartão magnético de débito pessoal, no qual as beneficiárias depositam $\mathrm{R} \$ 50,00$, mensalmente, para seus funcionários. (BRASIL, 2012b). Essa é uma política pública de cultura executada diretamente da esfera federal para o cidadão, sem a intermediação da gestão pública estadual e municipal.

Ressalta-se, porém, que o valor do cartão não constitui salário; não sofre desconto de contribuição previdenciária ou do FGTS e é isento de imposto de renda. (BRASIL, 2012b, 2013b). No entanto, o empregador pode descontar $\mathrm{R} \$ 1,00$ por salário mínimo recebido, dos trabalhadores com faixa salarial entre 1 e 5 salários mínimos. O Minc divulga como vantagem aos empresários a não geração de encargos calculados pela folha de pagamento dos funcionários. Nos termos da lei, "[...] não constitui base de incidência de contribuição previdenciária ou do Fundo de Garantia do Tempo de Serviço - FGTS." (BRASIL, 2012b, art. 11\%). Ou seja, o Estado está oferecendo como vantagem não cobrar encargos, sobre o valor investido pela iniciativa privada, na realização de uma política que é obrigação do Estado: a universalização do acesso à cultura.

As empresas beneficiárias optantes do regime tributário de lucro real podem isentar o valor depositado nos cartões Vale Cultura (R\$ $50,00 \mathrm{x} \mathrm{o}^{\circ}$ de funcionários x 12 meses), até o limite de $1 \%$ do 


\section{O VALE CULTURA NA VISÃO DE GESTORES DE EMPRESAS DE UM MUNICÍPIO DO SUL DO BRASIL}

Imposto de Renda sobre Pessoa Jurídica (IRPJ) devido. Essa isenção fiscal incide apenas sobre a primeira alíquota, de $15 \%$ do IRPJ. Tal limitação é determinada pela Lei ${ }^{0} 9.249$, de 26 de dezembro de 1995 (BRASIL, 2012b, art. 10º parágrafo $1^{\circ}$ ). Essa isenção será válida apenas "[...] até o exercício de 2017, ano calendário de 2016." (BRASIL, 2012b, art. $10^{\circ}$ ) e não se aplica ao valor gasto com a taxa administrativa paga para a empresa operadora.

O valor total de depósitos do Vale Cultura para os funcionários pode ser incluído como despesa operacional 3 e, dessa forma, reduzir o lucro real (faturamento - total de despesas $=$ lucro real) para o cálculo do IRPJ. Mas esse valor não pode ser incluído no cálculo da Contribuição Social sobre o Lucro Líquido (CSLL), que é de 15\% para entidades financeiras e de 9\% para as demais empresas (Receita Federal). Então, o cálculo de CSLL a pagar desconsidera a despesa com o Vale Cultura. (BRASIL, 2012b, art. $10^{\circ}$, parágrafo $3^{\circ}$ ).

Por todo o exposto acima, percebe-se que a isenção possível para as despesas com o Vale Cultura é bastante limitada. O impacto que isso terá sobre as empresas só poderá ser avaliado mediante um estudo de viabilidade econômica da situação real de cada empresa.

\subsection{Rede credenciada e empresas recebedoras em Itajaí}

A cidade de Itajaí é atendida pelas seguintes operadoras, por ordem de empresas recebedoras credenciadas: Alelo/Banco do Brasil (que atuam juntas em Itajaí) com 28 credenciadas na região; Ticket com 10 recebedoras; Banrisul com oito; Sodexo com 7 e Brasil Convênios com 3 empresas credenciadas. Esses dados foram obtidos estudando os sites dessas operadoras e identificando a quantidade e localização da rede credenciada.

A lista de empresas beneficiárias, no site do Vale Cultura, indica qual a operadora de cartão contratada. (BRASIL, 2015a). Desse modo, foi possível identificar quantas empresas beneficiárias, em todo o país, são atendidas por cada uma das cinco operadoras atuantes em Itajaí. A operadora Alelo atende 1144 beneficiárias em todo o país e o Banco do Brasil atende 1061. Essas duas empresas, juntas, detêm a maior fatia do mercado brasileiro de cartões Vale Cultura, cerca de $23 \%$. A operadora Ticket atende 823 beneficiárias no país, a Sodexo atende 773, o Banrisul 205, e o Brasil Convênios atende 33. Chama a atenção que o Banco do Brasil seja ao mesmo tempo, a segunda maior operadora do país e uma das maiores empresas beneficiárias. Seus fun- 
cionários nas mais de 5 mil agências recebem o cartão Vale Cultura. Sendo operadora de si própria, a taxa de administração do referido cartão tende a ser a menor permitida por lei, que é $0 \%$. Os recursos assim investidos retornarão das seguintes formas: os depósitos de $\mathrm{R} \$ 50,00$ nos cartões entram como despesa operacional e diminuem o lucro líquido. Bancos que são optantes do lucro real têm direito à isenção de $1 \%$ do imposto de renda devido sobre o lucro. Por outro lado, ao atuar como operadora, a distribuição do cartão Vale Cultura torna-se uma nova fonte de receita pela cobrança de taxa administrativa das empresas recebedoras credenciadas e beneficiárias para as quais fornecerem o cartão. Então, observa-se que, para o setor bancário, o Programa de Cultura do Trabalhador parece muito mais vantajoso do que para empresas de outros segmentos.

No caso de empresas recebedoras, que formam redes regionais ou nacionais e comercializam produtos culturais, elas também são beneficiárias por distribuir o cartão Vale Cultura aos seus funcionários. Uma parte dos recursos investidos no fornecimento desse benefício retornará com a comercialização de seus produtos aos próprios funcionários. Como empresas de grande porte, tendem a ser tributadas com base no lucro real, com direito à isenção de $1 \%$ no imposto de renda devido. Duas redes de cinemas e uma de livrarias que atuam nos estados da região sul do Brasil foram cadastradas por quatro das cinco empresas operadoras atuantes em Itajaí e Balneário Camboriú.

A rede de recebedoras local comercializa os seguintes produtos e serviços culturais: instrumentos musicais; apresentação de música eletrônica; ingressos pela internet; jornal; cinema; equipamentos; livros; revista; cursos e artesanato, com predominância do comércio de livrarias e papelarias. Itajaí tem, historicamente, grande produção cultural nos segmentos do teatro, música e dança, com muitos artistas e grupos constituídos em pessoas jurídicas, por meio de empresas ou associações. (MARQUES, 2013). Essa produção local não está representada na rede credenciada do Vale Cultura. Portanto, o desenvolvimento da autonomia cultural pela utilização desse cartão será bastante restrito enquanto as opções de acesso à cultura forem limitadas. 


\section{O VALE CULTURA NA VISÃO DE GESTORES DE EMPRESAS DE UM MUNICÍPIO DO SUL DO BRASIL}

2.4 Resultados da pesquisa: a percepção dos gestores sobre o Programa de Cultura do Trabalhador

Quanto à fonte de informação dos entrevistados, os dados indicam a 'imprensa', em propagandas oficiais (VALE CULTURA, 2014), como meio de comunicação com maior alcance para todas as categorias de participantes da pesquisa $(100 \%$ da categoria $\mathrm{RH}$; $50 \%$ da categoria Contábil e $75 \%$ da categoria Diretoria). As informações obtidas por essa via foram introdutórias, parciais e voltadas aos trabalhadores. Portanto, essa fonte não possibilita profundidade suficiente para respaldar a tomada de decisão dos gestores em aderir ou não ao Programa de Cultura do Trabalhador. Nenhum gestor indicou o site do MinC/Vale Cultura como fonte de informação.

Verificou-se, também, que o site do MinC não estabelece vias de comunicação direta com os gestores. Não existem links entre a plataforma digital do Ministério da Cultura (MinC) (Disponível em: $<$ http://www.cultura.gov.br/valecultura $>$ ) e o site da Receita Federal (diariamente acessado pelos gestores da área contábil), ou com os sites de federações empresariais e entidades representativas da área de recursos humanos.

Evidencia-se, portanto, uma falha na comunicação pública4 entre o MinC e as empresas, considerando que o Programa de Cultura do Trabalhador visa garantir a implementação de direitos culturais aos trabalhadores (BRASIL, 2013a) e que o exercício desses direitos de acesso e autonomia de consumo cultural se estabelecerão a partir da adesão das empresas ao programa. A falta de comunicação iniciada por parte do governo federal indica que o estímulo governamental para a adesão das empresas ao Vale Cultura é baixo.

Nenhum dos participantes respondentes conseguiu delinear o Programa de Cultura do Trabalhador quanto ao seu conceito, objetivos e normativa de funcionamento. As respostas de todos os participantes apresentaram fragmentos de compreensão sobre essa política. Conforme as falas dos interlocutores: "[...] Tudo envolvendo a cultura da região ou do país." (Informação verbal) ${ }^{7}$; "[...] Cartão para incentivo à cultura." (Informação verbal) ${ }^{8}$. Como explicitado anteriormente, isso confirma a avaliação de que a imprensa não é uma fonte de informação com profundidade suficiente para possibilitar a compreensão integral dessa política. 
Ana Clara Ferreira Marques | Maria Glória Dittrich

Micheline Ramos de Oliveira | Flávio Ramos

Os participantes da categoria RH embora tenham, na primeira questão, declarado conhecimento sobre o Programa de Cultura do Trabalhador, demonstraram, aqui, a superficialidade de tal conhecimento e também não conseguiram descrever inteiramente essa política. As falas evidenciaram vários equívocos acerca da normativa do programa, por exemplo: A noção de cultura não foi percebida como um direito. $\mathrm{O}$ Vale Cultura foi citado como um programa de subsídio do governo para as empresas devido à isenção fiscal, de acordo com a fala: "O pouco que conheço é a empresa recebe um subsídio né? [...] Pra distribuir ou dar ao funcionário a condição de ter acesso à algum tipo de cultura." (Informação verbal)

Outro equívoco foi a identificação do público alvo, que foi citado como sendo qualquer pessoa com renda entre 1 e 5 salários mínimos, o que pode ser evidenciado na fala a seguir: "[...] Todos os funcionários, não todo povo que tivesse renda menos de cinco salários mínimos pudesse ter alcance a leituras, a livros cinema e teatro." (Informação verbal) ${ }^{10}$. 0 programa destina-se exclusivamente aos trabalhadores com vínculo empregatício definido pela CLT (consolidação das leis do trabalho). Portanto, não têm direito ao Vale Cultura, autônomos, trabalhadores da economia informal e aposentados. (BRASIL, 2015b).

A percepção de benefício econômico para a empresa relacionada à isenção de imposto de renda (IR) ocorre de forma muito vaga e sem detalhamento, para os participantes da categoria $\mathrm{RH}$. Esse desconhecimento dificulta uma eventual defesa da viabilidade e importância da implantação desse programa junto às áreas contábil e diretoria da empresa.

$\mathrm{Na}$ categoria Contábil, os fragmentos de informação focaram os aspectos econômico, tributário e contábil 
O VALE CULTURA NA VISÃO DE GESTORES DE EMPRESAS

DE UM MUNICÍPIO DO SUL DO BRASIL

do Programa de Cultura do Trabalhador, trazendo mais dados

do que os entrevistados das demais categorias. Em termos

econômicos, a ênfase foi sobre os benefícios e limitações

que recaem sobre a empresa. Como pode ser averiguado no

discurso: "A empresa com certeza vai se beneficiar tendo os

colaboradores tendo acesso à cultura." (Informação verbal) ${ }^{11}$.

Não houve tentativa de expressar o conceito

de cultura, ou definir seu aspecto simbólico. A identificação

de serviços culturais foi feita de forma breve, apenas para dar

sentido à fala, e não propriamente pela importância do acesso à

cultura para a qualidade de vida do trabalhador. A dimensão da

cidadania foi tocada brevemente em relação à possibilidade de

autonomia de consumo cultural.

O consumo da arte possibilita a ampliação do capital intelectual (repertório de vivências e conhecimentos) do espectador. Mas também o torna um agente social, pois ao consumir a arte, o trabalhador dá sentido, propósito e ressignificação a ela. (RUBIM, 2010).

As respostas evidenciam que os participantes contábeis também não detêm informação completa sobre o Programa de Cultura do Trabalhador para se posicionar de forma conclusiva sobre a viabilidade de adesão ou não ao programa.

Entre os entrevistados da categoria Diretoria, a tentativa de delineamento do que abrange a cultura limitou-se à indicação do uso do cartão, em serviços e produtos que fazem parte da dimensão simbólica do termo cultura. Os mais citados foram cinema, teatro e shows. As respostas indicaram que não há a percepção de que o acesso à cultura é um direito constitucional de todo cidadão, essencial para o desenvolvimento integral do trabalhador.

Apenas 2 (33,3\%), dos 6 entrevistados, expressaram a percepção da existência de benefício para a empresa na adesão ao Programa de Cultura do Trabalhador. Esse benefício foi indicado como sendo de ordem tributária. Mas mesmo nesse aspecto, faltam clareza 
e profundidade de informações sobre a factibilidade econômica do Programa de Cultura do Trabalhador, que é questão central para a decisão de adesão à mencionada política. Compreende-se, portanto, que os diretores entrevistados, por seu desconhecimento, ainda não se percebem como agentes de construção da democracia cultural defendida por Calabre (2007).

Entre os participantes da categoria Funcionários, que conhecem o programa, essa política é vista como um benefício econômico para a empresa e para os funcionários. Mas não existe compreensão do montante de investimentos e/ou viabilidade econômica da adesão ao programa. Trazem a ideia incorreta (estimulada pela propaganda) de que os custos da empresa serão totalmente compensados pelo incentivo fiscal. Não foi manifesta a percepção da cultura como um direito constitucional, mas sim como incentivo ao acesso.

A categoria Contábil citou como benefícios ao funcionário o contato com a diversidade cultural; a inclusão cultural da família; o incentivo ao acesso à cultura; a autonomia de consumo; a ampliação de conhecimentos e o crescimento pessoal e comportamental. A categoria Diretoria percebe que o contato com a cultura gera melhoria na qualidade de vida e amplia a capacidade do funcionário em contribuir para a sociedade de forma geral. Os entrevistados anteveem que a consequência desses benefícios é a melhoria do desempenho dos funcionários dentro da empresa e o consequente aumento de produtividade.

Em contraponto aos benefícios indicados na categoria Contábil, um dos entrevistados aponta que o limitado número de empresas recebedoras credenciadas reduz o benefício para os funcionários do uso do cartão Vale Cultura. De fato, a cadeia produtiva da cultura formada por artistas locais ainda não foi incluída, visto que estão cadastradas apenas redes de empresas do segmento de comércio, fornecedoras de produtos culturais.

Na categoria Diretoria, dois entrevistados $(33,3 \%)$ alegam que os benefícios não seriam percebidos pelos funcionários devido ao seu desinteresse pela cultura. Nesse sentido, o discurso do diretor, a seguir, indica uma compreensão elitista de cultura: "Hoje 90\% da minha população, ou seja, os meus colaboradores são pessoas operacionais. Foi descartado, inviabilizado por essa questão, de não ter aderência ao nosso público." (Informação verbal) ${ }^{12}$. 


\section{O VALE CULTURA NA VISÃO DE GESTORES DE EMPRESAS DE UM MUNICÍPIO DO SUL DO BRASIL}

Esse argumento, além de equivocado, é apenas uma suposição, pois nenhuma das empresas participantes da pesquisa ofereceu o cartão Vale Cultura aos seus funcionários. Os autores Bourdieu e Darbel consideram que a necessidade cultural se intensifica com o convívio e familiaridade com as manifestações culturais. E, ao contrário, "[...] a falta de prática é acompanhada pela ausência do sentimento de privação [...]" (BOURDIEU; DARBEL, 2003, p. 69). O Programa de Cultura do Trabalhador tem por objetivo, justamente, possibilitar essa familiaridade pela autonomia de consumo e facilitação do acesso a uma gama bastante diversa de manifestações culturais.

Cabe salientar que a totalidade dos entrevistados da categoria $\mathrm{RH}$ indicou que, para atingir os objetivos do setor de RH/Gestão de Pessoas e os da empresa, a vantagem imediata é a motivação do funcionário pela percepção de estar ganhando mais um benefício. A consequência da motivação é a retenção do funcionário na empresa.

Quanto às desvantagens, cinco entrevistados $(62,5 \%)$ consideram que para o setor de RH/ Gestão de Pessoas não há desvantagens, na adesão ao programa. Por outro lado, indicou-se a pequena rede credenciada na região, e, o possível descontentamento dos funcionários com o valor do depósito mensal $(\mathrm{R} \$ 50,00)$.

Nesse sentido, há uma questão muito relevante para o RH, que é o equilíbrio entre o investimento e a efetividade das ações de gestão de pessoas e comunicação interna. A possibilidade de o trabalhador ficar descontente com o valor retira a efetividade desse benefício, até porque esse montante é determinado por lei e não pode ser alterado.

Em relação à viabilidade econômica do investimento no cartão Vale Cultura, a princípio as empresas apontam que não seriam capazes de oferecê-lo para todos os funcionários, na faixa de 1 a 5 salários mínimos, pois a isenção fiscal é muito pequena. Oferecer um benefício de forma segmentada gera descontentamento e incompreensão dos que não o recebem. E, por consequência, uma percepção de privilégios para alguns e desvalorização de outros, ou seja, a inefetividade do investimento. Então, para os entrevistados da categoria $\mathrm{RH}$, a viabilidade econômica é essencial para a implantação do programa, o que transfere a tomada de decisão para os participantes das categorias Contábil e Diretoria. 
Ana Clara Ferreira Marques | Maria Glória Dittrich

Micheline Ramos de Oliveira | Flávio Ramos

A avaliação inicial de factibilidade econômica realizada por dois participantes $(40 \%)$ dessa categoria indicam que não há vantagem com a isenção fiscal proposta, e sim, um custo considerável para a empresa. Explicitado na fala: "[...] não tem vantagem financeira, na verdade seria um custo." (Informação verbal) ${ }^{13}$. Alegam que o custo de um dever do Estado recairia inteiramente sobre a iniciativa privada. Então surge, aqui, o primeiro ponto de resistência à adesão das empresas ao Programa. Seja por desconhecimento ou pelo custo econômico dessa política, os entrevistados da categoria Contábil não manifestaram apoio consistente e transferem a decisão sobre a adesão ao Vale Cultura para a categoria Diretoria.

Esses, por sua vez, assumem uma postura bastante pragmática e de certa forma até ambígua. Consideram como vantagens estratégicas os benefícios que o acesso à cultura pode proporcionar ao funcionário e à empresa. Caso a isenção fiscal cobrisse os custos com o fornecimento do cartão, o aumento de produtividade, de motivação e de retenção dos funcionários seria alcançado com retorno do investimento na administração e divulgação do programa. Mas, diante da possibilidade concreta de que o Vale Cultura implique um investimento direto da empresa com pouca ou nenhuma vantagem fiscal, o benefício ao trabalhador parece se diluir no ar. A melhoria na qualidade de vida do trabalhador perde sua viabilidade prática. Os benefícios para a empresa são vistos já de maneira mais reticente.

Os participantes da categoria Diretoria apontam como desvantagem, ainda, a questão de que este seria um investimento da empresa sem retorno para o funcionário devido à diminuta rede credenciada de recebedoras do cartão Vale Cultura. Exemplificado na fala: "Ver restrita a utilização do vale cultura para apenas a opção 'cinema'." (Informação verbal) ${ }^{14}$. Esse argumento é pertinente, no presente momento, inclusive geograficamente, pois a distribuição dos credenciados pelos bairros do município é limitada, concentrando-se na região centro.

O baixo índice de detalhamento, por parte de $80 \%$ dos entrevistados, indica falta de conhecimento a respeito de como, efetivamente, funciona o programa. Isso compromete ou até impede a identificação da viabilidade econômica, dentro da realidade de cada empresa, para a adesão ao programa. Em consequência disso, os dados demonstram que entre os diretores das empresas, falta, também, uma informação aprofundada que embase uma tomada de decisão 


\section{O VALE CULTURA NA VISÃO DE GESTORES DE EMPRESAS \\ DE UM MUNICÍPIO DO SUL DO BRASIL}

criteriosa sobre a viabilidade da adesão ao Programa de Cultura do Trabalhador. Os dados acima apresentados indicam que tanto os participantes da categoria Contábil, quanto os da categoria Diretoria, identificam que a tomada de decisão sobre a adesão ao referido Programa envolve múltiplos fatores. Entretanto, os indícios apontam que os fatores de tributação têm maior peso na tomada de decisão dos gestores.

Outro aspecto é que o exercício dos direitos culturais de acesso e autonomia de consumo cultural é uma opção dos trabalhadores, que escolhem receber ou não o cartão Vale Cultura. O momento, a forma e o conteúdo da comunicação, acerca da implantação desse benefício na empresa, podem influir na porcentagem de adesão dos trabalhadores, na quantidade de cartões distribuídos e na viabilidade econômica da implementação do programa. De modo que os entrevistados da categoria RH foram consultados sobre esses aspectos da comunicação. Todas as respostas são hipotéticas, pois nenhuma das empresas participantes da pesquisa havia decidido pela adesão ao Programa de Cultura do Trabalhador.

Quanto ao momento da comunicação, $75 \%$ das respostas indicam uma grande preocupação em identificar o interesse de adesão dos funcionários pelo cartão Vale Cultura, antes de proceder sua implantação e o cadastramento da empresa junto ao ministério. $\mathrm{O}$ processo de consulta prévia faz com que esse benefício seja sentido como uma conquista dos próprios funcionários e o nível de rejeição tende a ser muito menor do que se o processo todo fosse imposto. Ao possibilitar a participação dos funcionários na decisão da implantação, esses estarão, por consequência, optando pelo usufruto ou não do seu direito de acesso à cultura.

Em relação à forma de comunicar a adesão ao Vale Cultura, os respondentes da categoria $\mathrm{RH}$ apontaram a utilização simultânea de diversos instrumentos de comunicação de que a empresa dispõe. Acerca do conteúdo da comunicação sobre qual informação específica seria transmitida aos funcionários, as respostas indicaram a existência de três focos comunicativos, que seriam: o funcionário (O que é o Vale Cultura? Como funciona? Onde usar?), a empresa (datas, prazos e procedimentos internos) e o conceito que embasa essa política.

Os dados indicam que a implantação do Programa de Cultura do Trabalhador não encontraria obstáculos nos profissionais do setor 
de RH das empresas. Entretanto, a aspiração de promover o acesso à cultura encontra-se num nível hipotético. Esse desejo cultural é cerceado pelo aspecto econômico, que se impõe como impedimento, mesmo sem um estudo aprofundado do tema, o que reduz a capacidade de ação para a adesão ao programa.

\section{CONCLUSÃO}

O Programa de Cultura do Trabalhador é uma política pública de cultura executada pelo governo federal, diretamente para o cidadão, sem a intermediação de níveis estaduais e municipais de gestão pública. A adesão ao programa é opcional às empresas e trabalhadores.

A importância de sua implantação no município de Itajaí é justamente o potencial dessa política que visa universalizar o acesso à cultura, estimular o financiamento direto da intensa produção artística local e regional, pela ampliação do mercado consumidor de cultura e injeção mensal de recursos. Além disso, é importante também pelo estímulo à autonomia de consumo cultural, e a consequente preservação do patrimônio que integre o contexto sociocultural e a percepção de qualidade de vida dos trabalhadores itajaienses.

Os participantes do RH, em sua maioria, consideram importante informar e estimular o interesse dos funcionários pelo programa e pela fruição cultural, antes de realizar o cadastramento. De maneira geral, esses gestores se mostram empenhados em utilizar todas as ferramentas de comunicação a sua disposição para a informação dos funcionários sobre a adesão ao Vale Cultura, quando e se essa decisão for tomada.

Os participantes contábeis apresentam resistência à implantação do Vale Cultura devido à reduzida isenção fiscal e aos custos desse investimento para a empresa. Os participantes da Diretoria não estão convencidos da viabilidade econômica da adesão ao programa e consideram que a rede credenciada reduzida anula o benefício do Programa de Cultura do Trabalhador. Logo, apesar do interesse dos funcionários, nenhuma empresa se decidiu ainda pela adesão ao Vale Cultura; não houve tentativa de cadastramento ou de contato com as empresas operadoras e nem mesmo o interesse por realizar uma pesquisa mais aprofundada sobre as normativas e a viabilidade de implantação dessa política. Conclui-se que o Programa de Cultura do Trabalhador não é de interesse focal para os gestores das empresas. 


\section{O VALE CULTURA NA VISÃO DE GESTORES DE EMPRESAS DE UM MUNICÍPIO DO SUL DO BRASIL}

O processo de implantação do Programa de Cultura do Trabalhador em Itajaí está em fase de tomada de consciência e do despertar do interesse empresarial.

As empresas operadoras têm papel central na eficiência da implantação dessa política. A ampliação significativa da rede credenciada de empresas recebedoras, incluindo todos os segmentos artísticos atuantes em Itajaí e região, é de grande importância para estimular a adesão de mais beneficiárias ao programa.

Portanto, sugere-se, como pesquisas futuras, um estudo de viabilidade econômica para diversos perfis empresarias existentes em Itajaí. E, também, a realização de pesquisa diretamente com as operadoras atuantes no município, para que haja uma maior compreensão sobre a formação da rede credenciada nessa região.

\section{REFERÊNCIAS}

BOURDIEU, P.; DARBEL, A. Amor pela arte: os museus de arte na Europa e seu público. Tradução Guilherme João de Freitas Teixeira. São Paulo: EDUSP; Porto Alegre: Zouk, 2003.

BRASIL. Constituição da República Federativa do Brasil: Texto constitucional promulgado em 5 de out. de 1988, com as alterações adotadas pelas Emendas Constitucionais $n^{\circ} 1 / 92$ a 64/2010, pelo Decreto $\mathrm{n}^{\circ}$ 186/2008 e pelas Emendas Constitucionais de Revisão $n^{\circ} 1$ a 6/94. Brasília, DF: Senado Federal, Subsecretaria de Edições Técnicas, 2012a.

Decreto ${ }^{\circ} 8.084$, de 26 de agosto de 2013. Regulamenta a Lei $\mathrm{n}^{\circ} 12.761$, de 27 de dezembro de 2012, que institui o Programa de Cultura do Trabalhador e cria o vale-cultura. Diário Oficial [da] República Federativa do Brasil, Brasília, DF, 27 ago. 2013b. Disponível em: <http://www.planalto.gov.br/ccivil 03/ Ato20112014/2013/Decreto/D8084.htm>. Acesso em: 10 maio 2014.

Lei $\mathrm{n}^{\circ} 12.343$, de 2 de dezembro de 2010. Institui o Plano Nacional de Cultura - PNC, cria o Sistema Nacional de Informações e Indicadores Culturais - SNIIC e dá outras providências. Diário Oficial [da] República Federativa do Brasil, Brasília, DF, 6 dez. 2010. Disponível em: <http://www2.camara.leg.br/legin/fed/lei/2010/lei12343-2-dezembro-2010-609611-norma-pl.html>. Acesso em: 10 maio 2014. 
. Lei $\mathrm{n}^{\circ} 12.761$, de 27 de dezembro de 2012. Institui o Programa de Cultura do Trabalhador; cria o vale-cultura; altera as Leis nos 8.212, de 24 de julho de 1991, e 7.713, de 22 de dezembro de 1988, e a Consolidação das Leis do Trabalho - CLT, aprovada pelo Decreto-Lei no 5.452, de $1^{\circ}$ de maio de 1943; e dá outras providências. Diário Oficial [da] República Federativa do Brasil, Brasília, DF, 27 dez. 2012b. Disponível em: <http://www.planalto.gov. br/ccivil_03/_Ato2011-2014/2012/Lei/L12761.htm>. Acesso em: 10 maio $20 \overline{14}$.

Ministério da Cultura. As metas do Plano Nacional de Cultura. 2. ed. São Paulo: Instituto Via Pública; Brasília, DF, $2013 a$.

Plataforma digital de cadastramento de empresas ao Programa de Cultura do Trabalhador. Brasília, DF, 2015a. Disponível em $<$ http://vale.cultura.gov.br/>. Acesso em: 15 ago. 2015.

Plataforma digital de informações sobre o Vale

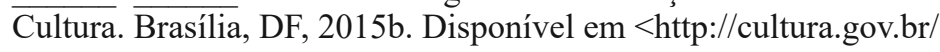
valecultura $>$. Acesso em: 15 ago. 2015.

. Ministério da Fazenda. Secretaria da Receita Federal do Brasil. Lucro real - conceito. Brasília, DF, [201-]. Disponível em <http://www.receita.fazenda.gov.br/pessoajuridica/dipj/2000/ orientacoes/lucroreal.htm>. Acesso em: 25 out. 2015.

CALABRE, L. Políticas culturais no Brasil: balanço e perspectivas. In: ENCONTRO DE ESTUDOS MULTIDISCIPLINARES EM CULTURA, 3., 2007, Salvador. Anais... Salvador: UFBA, 2007.

COELHO, T. Dicionário crítico de política cultural. São Paulo: Iluminuras, 1997.

DITRICH, M. G. A criatividade do amor criante de Deus: uma vivência de cura espiritual na criação artística. São Leopoldo: Escola Superior de Teologia, 2008.

DUARTE, J. (Org.). Comunicação pública: Estado, governo, sociedade e interesse público. São Paulo: Atlas, 2007.

INSTITUTO BRASILEIRO DE GEOGRAFIA E ESTATÍSTICA.

Cidades. Rio de Janeiro, 2010. Disponível em: <http://www.cidades. ibge.gov.br/xtras/perfil.php?lang $=\&$ codmun $=420820 \&$ search $=$ santacatarina|itajai>. Acesso em: 6 set. 2014.

MARQUES, A. C. F. Comunicação e formação de público para a arte - um estudo de caso no teatro municipal de Itajaí. In: CONGRESSO DA ASSOCIAÇÃO BRASILEIRA DE PESQUISADORES DE 


\section{O VALE CULTURA NA VISÃO DE GESTORES DE EMPRESAS DE UM MUNICÍPIO DO SUL DO BRASIL}

COMUNICAÇÃO ORGANIZACIONAL E RELAÇÕES PÚBLICAS, 7., 2013, Brasília, DF. Anais... Brasília, DF: ABRACORP, 2013. p.988-1007.

MERLEAU-PONTY, M. Fenomenologia da percepção. Tradução Carlos Alberto Ribeiro de Moura. 2. ed. São Paulo: Martins Fontes, 1999.

RUBIM, A. A. C. Políticas culturais: entre o possível \& o impossível. In: NUSSBAUMER, G. M. (Org.). Teorias e políticas de cultura: visões multidisciplinares. Salvador: EDUFBA, 2007. p.139-158.

Singularidades da formação em organização da cultura no Brasil. Organicom, São Paulo, v. 7, n. 13, p. 36-48, 2010.

VALE CULTURA comercial. Publicado por Tele Cine Video Store, 31 mar. 2014. (30s). Disponível em: <https://www.youtube.com/ watch?v=PuIzqTSx2yE>. Acesso em: 30 out. 2015.

\section{Notas}

1 É a base de cálculo do imposto sobre a renda apurada segundo registros contábeis e fiscais efetuados sistematicamente de acordo com as leis comerciais e fiscais (BRASIL, [201-]).

2 Art. $3^{\circ}$ da Lei 12.343 estabelece que "[...] compete ao poder público: Promover e estimular o contato e a fruição do público com a arte e a cultura de forma universal." (BRASIL, 2010, Artigo $3^{\circ}$ )

3 "São operacionais as despesas não computadas nos custos, necessárias à atividade da empresa e à manutenção da respectiva fonte produtora." (BRASIL, [201-])

4 Segundo Duarte (2007), comunicação pública é o esforço comunicativo iniciado pelo poder público, visando atingir toda a sociedade com informações de interesse do cidadão.

5 As identidades dos entrevistados e das empresas foram nominadas de forma alfanumérica. Os participantes foram identificados da seguinte forma: a letra inicial da categoria de gestão ('D' para direção, 'C' para contábil e 'R' para $R H$ ), seguido do número da empresa, indicado aleatoriamente

6 Depoimento retirada da fala da entrevista com o participante D6

Depoimento retirada da fala da entrevista com o participante D6

Depoimento retirada da fala da entrevista com o participante D4

Depoimento retirada da fala da entrevista com o participante R6

${ }^{10}$ Depoimento retirada da fala da entrevista com o participante R8

${ }^{11}$ Depoimento retirada da fala da entrevista com o participante $\mathrm{C} 1$

2 Depoimento retirada da fala da entrevista com o participante D6

${ }^{13}$ Depoimento retirada da fala da entrevista com o participante C.6

${ }^{14}$ Depoimento retirada da fala da entrevista com o participante D3 
